\title{
Quantitative Versus Qualitative Research Dichotomies: A Discussion from Educational Measurement and Evaluation Perspective
}

\author{
Brian Mumba $^{1 *} \quad$ Prof. Dr. Devrim ALICI ${ }^{2}$ \\ 1.Department of Research, University of Lusaka, 36711, Lusaka, Zambia \\ 2.Faculty of Education, Mersin University, 33110 Yenişehir/Mersin, Turkey \\ * E-mail of the corresponding author: brianmumba0@gmail.com
}

\begin{abstract}
How do we decide whether to use a quantitative or qualitative methodology for our study? Quantitative and qualitative research (are they a dichotomy or different ends on a continuum?). How do we analyse and write the results of a study for the research article or our thesis? Further questions can be asked such as; is the paradigm same as research design? How can we spot a paradigm in our research article? Although the questions are answered quietly explicitly, the discussion on the paradigm and research design remains technical. This can be evidenced by the confusion that people still face in differentiating between a paradigm, methodology, approach and design when doing research. The confusion is further worsened by the quantitative versus qualitative research dichotomies. This article addresses quantitative and qualitative research while discussing scientific research paradigms from educational measurement and evaluation perspective.
\end{abstract}

Keywords: Paradigm, Methodology, Approach, Quantitative, Qualitative

DOI: $10.7176 /$ RHSS/11-24-01

Publication date: December $31^{\text {st }} 2021$

\section{Introduction}

Several professionals in the measurement and evaluation field devote a considerable amount of their time in developing, administering, and interpreting tests. A major aspect of their work ranges from test construction in the education field to developing assessment in employment settings to identify personality traits. From the general point of view, all researchers need to be proficient in measurement this is because most research, regardless of its focus (e.g., social interactions, child development, cognitive development or animal behaviour) involves measurement and/or assessment. That is, whether a researcher is concerned with behavioural response time, visual acuity, intelligence, or depressed mood, he or she will need to engage in measurement as part of the research. This being the case, one can argue that scientific research and measurement are inseparable. For one to be successful at the research he or she has to know measurement. Conversely, to be successful in measurement one has to have scientific research knowledge. Research by its nature is knowledge production and how this knowledge is produced is one of the questions that the paper attempts to answer in discussing scientific research paradigms. To answer these questions and others not asked here, the paper is organized as follow. The first part examines the term paradigm and the main paradigms in scientific research. The third part discusses the differences between the key terms' paradigm, methodology, approach and design as used in research. Fourthly, is a discussion on quantitative and qualitative dichotomy (should they be considered as a dichotomy or different ends on a continuum?). Last but not least the paper discusses scientific research paradigms from educational measurement and evaluation perspective.

\section{Scientific Research Paradigm}

When examining the history of science and knowledge often encountered is a heated debate and discussion on what should form scientific knowledge and how this knowledge should be collected, especially in social sciences. This debate is especially on the knowledge and the nature of science. The debate is further worsened by technical terms used in differentiating key terms such as paradigm, approach, and methodology and research design. For instance, Smith (1981, p.45) defined research as a "disciplined inquiry that must be conducted and reported carefully". Implied in this definition is that this something known as research has certain plans and procedures that must guide the entire process from research decisions through research design to detailed procedures of data collection and analysis.

What this means is that research inquiry either for journal article publication or thesis or other aims has some steps that must be followed, and these steps cannot be taken in the order in which they make sense to us and the manner of presentation that one desires so. Most often, the overall manner involves answering the questions of the design to be used to study a given topic of interest. Behind this decision is the paradigm that the researcher holds, that guides a given research design and which further inform us on the specific techniques for collecting data, doing analysis, and interpreting the findings (Creswell, 2014). 
According to Christensen, Johnson, and Turner (2014), the selection of a research approach and its design is further influenced by the nature of the research problem or issue that is of interest to the researcher, individual experiences, and to a larger extent the participants for the study. Hence, to fully understand the selection process it is important to discuss some key terms that are a source of confusion to many people in research fields. This section, thus, examines the term paradigm.

\subsection{Paradigm}

The word paradigm can be traced to Kuhn's theory of science. However, according to (Smith, 1992, p.91), Kuhn did not introduce the word "paradigm" but he chose it. As Kuhn (1996, p.24) himself indicated "I choose the word paradigm" to describe past scientific achievements because it was closely related to what he called normal science. Thus, the term was already an established term, which meant literary an illustrative example of something, on which other cases can be modelled. Kuhn discussed and finetuned the original meaning of the term while examining the structure of scientific revolution. A paradigm in this sense means something like a way of seeing the world and interacting with it (Smith, 1992).

Smith (1992, p.91) summarizing Kuhn's theory defines a paradigm as a "package of claims about the world, methods for gathering and analysing data, and habits of scientific thought and action". Furthermore, it is imperative to note that Kuhn used the term "paradigm in more than one sense. For instance, Margret Masterman, in her article titled "The Nature of a Paradigm", identified about 21 possible meanings for a paradigm in the book (Masterman, 1970). However, she compressed the senses into three different categories, namely metaphysical (meta-paradigm), the sociological, and the art factual, and according to her, only the third closely related to what Kuhn had in mind (Masterman, 1970). It can be said that since the introduction of the term, multiple definitions of paradigm have existed that are problematic to understand especially outside the philosophical field. However, if one asks what a paradigm does, it becomes clearer at once, that it assumes the existence of normal science related to the artefactual sense. In Masterman's words, a paradigm is "a concrete picture used analogically since it has got to be a way of seeing" (Masterman, 1970, pp.58).

Smith (1992), further indicates that "Kuhn later agreed that he had used the word ambiguously, and throughout his career, he kept finetuning this and other key concepts" (p.92). Thus, to keep things simple, he adopts two main different senses of the term "paradigm." The first sense is called the broad sense, which is the one described above. Here, a paradigm is a belief of ideas and methods, which, when combined, makeup both a view of the world and a way of doing science (Smith, 1992). Kuhn (1996) described the second senses a narrow sense, which is a specific part of paradigm within the broad sense called specific achievement, or an exemplary. The specific achievement might be performing a successful experiment, such as Mendel's experiments or formulating a set of laws such as Newton's laws of motion or formulating the set of equations like Maxwell's equations describing electromagnetism (Smith, 1992). In other words, whatever it is, the specific achievement is a source of inspiration to others; suggesting a way to discover the world. Thus, paradigms in the broad sense (as a whole way of doing science) include within them, paradigms in the narrow sense e.g., specific achievements that serve as models, inspiring and directing further work. However, Kuhn himself did not use this "narrow/broad" terminology (Smith, 1992), but it is helpful for a better understanding of a paradigm.

The main topic of interest in this paper is Kuhn's usage of the phrase "normal science" describing scientific work that occurs within the framework provided by a paradigm. Thus, a key feature of normal science is that it is well organized, with scientists in the research community agreeing or disagreeing on which problems are important, on how to approach these problems, and on how to assess possible solutions. Those doing scientific work also agree on what the world is like, at least in broad outlines. On the other hand, (Kuhn, 1996, pp.36-40) argued that breakthrough also occurs after the discovery of anomalies making scientists question the paradigm, and this, in turn, leads to a scientific revolution that he termed paradigm shift, e.g., the shift from the positivist to postpositivist (this is was seen as large shift across various fields.

To further understand the term paradigm, is a comprehensive discourse by (Guba and Lincoln, 1994; Gliner et al., 2017), who describe paradigm as a set of basic beliefs of the individual in its most general form. Implied in this general definition is the point that paradigm reflects an individual's knowledge, that is, everyone has some understanding about the world and its relationships. From a more specific side is Gliner et al., (2017), with the definition of a paradigm as a whole of beliefs, values, techniques and similar elements shared by the members of society as a whole of the assumptions related to the social environment revealed by the philosophical and conceptual foundations. The above points are connected to (Ergül, 2019, pp.4) who advanced that "paradigm can be considered as systems that meet the need to shape and make sense of reality. Thus, areas such as sociology, psychology or educational science can be called popular paradigms within sciences with their assumptions and a group of people believing them as they try to find answers to problems in their fields.

Thus, paradigm, in terms of its general structure, refers to an individual perspective that can develop over time and become general. More importantly, paradigms are more functional in generating concepts for the meaning and clarification of reality rather than answering the fundamental questions about reality. This is a 
justification for the claim that all scientific developments are shaped based on a paradigm. Hence, to end this discussion, a paradigm is put as the manner of thinking about and conducting research. However, this is not to say that it is a methodology but as something that guides a methodology. Meaning that a methodology is part of the paradigm concerned with answering questions of how we study and discover knowledge.

\subsection{Scientific Research Paradigms}

All research needs some precise knowledge at the beginning of the project. This basic knowledge guides the researcher's assumptions about how they will learn and what they will learn during their project. These are also called "World Views" (Creswell, 2013, pp.13). Denzin and Lincoln (2005) illustrate that paradigm is part of human constructions or beliefs that can be never be established in terms of their ultimate existence. The two further puts it that paradigm as a belief is made up of four philosophical terms, that is, ethics, epistemology, ontology and methodology (Denzin and Lincoln, 2005). Ontology is philosophically concerned with the nature of reality. Hence, different paradigms consider reality differently (Lichtman, 2006). For instance, the positivist accepts an objective reality. Postpositivist, on the other hand, would accept that reality can only be reached imperfectly but researchers would strive to reach it. Constructivist speak of relativism and constructed realities. Paradigms that are participatory speak of realities that are created by both the participants and the researcher (Lichtman, 2006).

Epistemology is related to knowledge generation. Thus, it questions how knowledge is produced philosophically. Christensen et al., (2014) grouped the sources of knowledge into three areas experience, expert opinion and reasoning. For instance, we have the positivist taking the deductive approach to knowledge creation and the constructivist taking the inductive approach. Values and ethics relate to values held by the researchers and the extent to which it is possible or desirable to keep those values from influencing aspects of the research body. Cohen et al. (2007, pp.27), "values and ethics further relate to human nature and the relationship between human beings and their environment". A human being is both the subject and object of the study. Two things are clear here; one group of researchers see human beings as the product of the environment controlled like puppets, and the other group see them as initiators of their actions with free will and creativity producing their environment (Cohen et al., 2007). Thus, the postpositivists see human beings as an object that needs to be controlled to be studied. On the other hand, the constructivists see human beings as part of the research process who can be involved at all stages of the research process.

Lichtman (2006) argues that both qualitative and quantitative researchers operate within a certain value system. The other issues related to the values are concerned with the role of the research subjects. Thus, it seeks to answer questions of the level of involvement participants can and should have in research and how to protect them. However, Denzin and Lincoln (2005) argue that philosophically, claims such as what is knowledge (ontology), how we know it (epistemology), what values go into it (axiology or ethics), how we write about it (rhetoric), and the processes for studying it (methodology) can never be fully answered or established in terms of their ultimate existence. Denzin and Lincoln (2000) mentioned four major paradigms: (1) positivism/postpositivism, (2) constructivism, (3) advocacy participatory, and (4) pragmatism. Each of these has developed criteria, assumptions and methodology. Lichtman (2006) summarises by noting that all of these paradigms must address the philosophical issues, that is, ethics, ontology, epistemology and methodology. However, these paradigms are not discussed in this article. For further reading on these see (Christensen et al., 2014; Kothari, 2004; Creswell, 2014).

\section{Methodology, Approach and Design}

Earlier in the paper, it has been pointed out that four philosophical terms make up a paradigm; ethics, epistemology, ontology and methodology. Already from here, one can simply define methodology as a philosophy answering questions of how knowledge is discovered. The main distinction between a paradigm and methodology is that the former is a belief, functional in generating concepts for the meaning and clarification of reality. The latter is a philosophy answering questions of how knowledge is discovered, to a larger extent influenced by ethics, epistemology, and ontology. Cohen et al. (2007) note the three have direct implications for methodology, as contrasting ontologies, epistemologies and ethics, in turn, demand different research methodologies.

For instance, those who view the world as a natural phenomenon is hard, real and external to the individual will adopt the quantitative, objective or positive methodology. Those who view the world as social being much softer, personal and humanly created will adopt the qualitative, subjective or constructive methodology. On the other hand, those who view the world as a social reality interested in the subjective experience of individuals in the creation of the world, relativistic of the social world rather than an absolute, external reality will adopt a mixed-method (quantitative and qualitative) in searching the world using different methods and approaches (Burrell and Morgan, 1979). Thus, it is very clear that, in reviewing ontology, epistemology, ethics and methodology, three ways concerning the search for reality in the world exists: the quantitative, qualitative and 
mixed research methodology.

Kothari (2004) defined methodology as a way to systematically solve the research problem. It is further put as a science for studying how research is done scientifically. Thus, in studying methodology one can master the steps that are generally adopted by researchers in studying research problems along with the logic behind them. There is a confusion between a methodology and an approach. Among the main authors of scientific research methods books reviewed, no direct definition of approach has been given. However, from the simple logical as found in Lichtman (2006), an approach can be defined as a way to do a particular methodology. This makes sense because the methodology has been divided into three; quantitative, qualitative and mixed methodology. Cambridge Dictionary defines an approach as a verb "to deal with something". Thus, an approach is a way to deal with a particular problem within a given methodology.

Therefore, within each methodology, we can find many approaches. For instance, within the quantitative methodology, we find the experimental, quasi-experimental, comparative, associational, and descriptive approach among many others. Within the qualitative, we find case studies, ethnography, phenomenology, mixed methods, and many others. Thus, an approach is found within a methodology with qualitative and quantitative methodologies having their approaches. On the other hand, research methodology addresses the ontological, epistemological and ethical questions within the paradigm.

Other terms confused with the methodology are research method and design. Kothari (2004) defined research methods as including all those methods or techniques that can be used to conduct research. Thus, all those methods the researcher uses in solving research problems are categorized as research methods. Research design on the hand is concerned with the what, where, when, how much and by what means concerning an inquiry or research study. Kothari (2004), defined research design as a blueprint for the collection, measurement and analysis of data. Briefly, a research design must at least contain the following; a clear statement of the research problem; procedure and techniques to be used for gathering information; population to be studied; and methods to be used in the processing and analyzing of data (Kothari, 2004).

Before closing this discussion, maybe some of us maybe wondering with the question of why tangling ourselves up in philosophy, theories, and politics on paradigms. Why taking so much time talking about the paradigms, methodology, approach and design? The simple answer is that researcher's philosophical orientation has implications for every decision made in the research process, including the choice of methodology, approach and design as figure 1 illustrates. On the contrary, it would be also true for other researchers to proceed without an understanding of scientific research paradigms or their associated philosophical assumptions. However, as Bother (2011) puts it working without an awareness of our underlying philosophical assumptions imply working with these paradigms blindly.

This is so because working without having the knowledge of scientific research paradigms and their assumptions does not mean that one does not have such assumptions, only that one is conducting research that rests on unexamined and unrecognized assumptions. Which one is better; working with the knowledge of these paradigms or working without an awareness? Consequently, it would be alright to end with the point that scientific research paradigms are inseparable with the research methods. That is, for one to plan and conduct his or her research, read and critique the research of others, and join in the philosophical, theoretical, and methodological debates in the research community, he or she need to have an understanding of the prevailing paradigms, with their underlying philosophical assumptions.

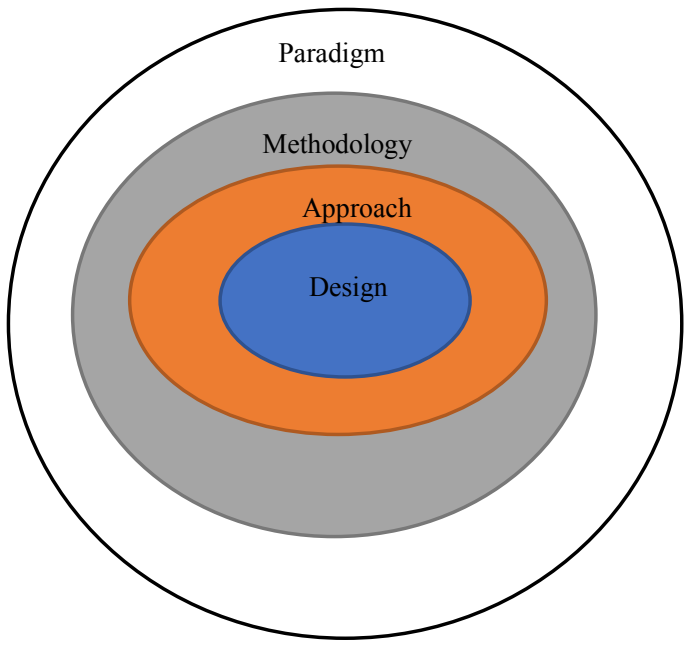

Figure 1. Paradigm, Methodology, Approach and Design Summary 


\section{Quantitative versus Qualitative Research (a Dichotomy or Continuum?)}

The first debate on qualitative-quantitative research in educational research can be traced back as far as 1844 when Auguste Comte claimed that the methods of natural science could be justified in studying social science. Auguste Comte viewed science as a study and collection of facts based on sensory input (Newman and Benz, 1998). For Comte, the only data that must be of concern is the data investigated by natural scientists like the physicists, the chemists, the biologists among others (Biggerstaff, 2012). Thus, in Comte's view, true science is accumulated through the study of phenomena that can be physically sensed, observed, and counted. Contributing to the debate is Herbert Spencer who first introduced the term "The unknowable" in his 1910 essay describing "those things that cannot be sensed or which cannot be known by our intelligence" but might rely on reason or thought, and that should be banished from the scientific investigation (Hoy and Adams, 2015, pp.10). We see that the debate was on what should form the scientific data, we have Spencer describing qualitative data and Comte on the other hand quantitative data. However, the two Comte and Spencer were positivists who seemed to have argued that the constructivists had no place in the scientific investigation (Newman and Benz, 1998).

Furthermore, Newman and Benz (1998) indicated that the current debate on the qualitative versus quantitative research methods has some philosophical roots in the naturalistic and the positivistic philosophies, respectively. The debate came following the counter-arguments by the constructivist towards the positivist paradigm as discussed earlier in the paper. Newman and Benz (1998) argue that qualitative researchers, regardless of their theoretical differences, reflect some sort of individual phenomenological perspective. On the other hand, Creswell (2013) notes that all quantitative research approaches, regardless of their theoretical differences, have a common reality on which people can agree. From the qualitative perspective is Lichtman (2006) who believes in the concept of multiple realities and argue that multiple interpretations are available from different individuals that are all equally valid and cannot be ignored. Thus, for qualitative researcher reality is a social construct. Simply put, there are different degrees of belief in various sets of assumptions about reality among qualitative and quantitative researchers. For instance, Blumer (1980) a qualitative researcher emphasized subjectivity, without denying that there is a reality one must strive to reach. According to Newman and Benz (1998), the debate between qualitative and quantitative researchers is embedded in the differences in assumptions about what reality is and whether or not it is measurable. Thus, the debate mainly lies in the differences of views about how best we can discover knowledge whether through the objective or subjective methodology.

Today the quantitative versus qualitative debate has continued as though one or the other should eventually win. Hurwitz (1995) argues that discontinuing the debate is not the issue of importance but the focus should be on improving the quality of research through an integrated approach of looking at qualitative and quantitative research methods. According to Newman and Benz (1998) and Hurwitz (1995), both qualitative and quantitative coexist in the world of inquiry and together form an interactive continuum. The two argued that categorizing the two as a dichotomy is false. Firestone (1987) in an article in the Educational Research, differentiates qualitative from quantitative research methods based on four dimensions, that is, assumptions, purpose, approach, and research role. Firestone (1987) asks different questions, for instance, regarding assumptions, is objective reality sought through facts or is reality socially constructed? On the purpose, he asks: is it looking for causes or understanding? Regarding approach, he asks whether the research is experimental/associational or a form of a case study. Lastly, related to the researcher's responsibility, he asks whether the researcher is detached or immersed in the setting (Firestone,1987). Firestone in his article does not give any position regarding whether categorizing them as a dichotomy or a continuum. However, looking at the differences it is clear Firestone looked at them as a dichotomy.

Most recently is Gliner and Morgan (2000) who categorised them as dichotomy on three levels with the first one being the philosophical or paradigm differences in the approach to research (positivists versus constructivists or quantitative versus qualitative philosophies). Secondly, is the confusion of the paradigm distinction (quantitative versus qualitative philosophies) mixed with the type of data and data collection techniques (quantitative versus qualitative data and data collection). And the third one is the dichotomy about how data are analysed and interpreted (quantitative versus qualitative data analysis). For further reading see (Mumba and Alıc1, 2019).

Shaker (1990) like Newman and Benz (1998) and Hurwitz (1995) categorised them on a continuum using a metaphorical journey moving from quantitative perspectives in the past to more recent naturalistic and qualitative assumptions. Though Shaker was arguing from the program evaluation perspective, he posited the two on a chronological continuum, with no opposition to the notion of question-driven research and evaluation (Shaker, 1990). Newman and Benz (1998) argue that while Shaker described the "new identity" for evaluation as being based on naturalistic approaches, he placed this in the context of a pragmatic commitment to finding methods that yield results in practice as we find it, rather than as we wish it to be. Thus, among the literature reviewed we have those categorising qualitative versus quantitative research as a dichotomy. Contrary to dichotomy position is Newman and Benz (1998); Hurwitz (1995) and Shaker (1990) among others who 
categorised them on a continuum. Hence, in this paper, we take the position of a continuum. This is because taking them as a dichotomy would imply that the two are mutually exclusive. This is related to the position by Lichtman (2006) who argues that the two philosophies (qualitative versus quantitative methodology) are neither mutually exclusive (e.g., one need not commit to either one or the other) nor interchangeable (e.g., one cannot merge methodologies with no concern for underlying assumptions). Newman and Benz (1998) present an interactive place on a methodological and philosophical continuum based on the philosophy of science. For instance, a researcher tests theory and feedback the results to the original hypothesis, while using both the inductive and deductive processes at different points in time. That is, both qualitative and quantitative methods are invoked at different points in time through feedback loops aimed at maximizing the validity of the study.

\section{A Discussion from Educational Measurement and Evaluation Perspective}

In the introduction, it has been argued that all area of science is very concerned with and/or dependent on measurement. Why is this the case? This is because the science of measurement enacts its necessity by becoming a prerequisite, not only for the scientist conducting research but also for the practitioners trying to apply scientific theories and methods for social development and academic enrichment (Chadha, 2009). Scientific research is concerned with the development of knowledge which is objective, exact and verifiable. Thus, the aim of researchers in educational measurement or those in any scientific inquiry is to collect facts about an object or a phenomenon or a system or a problem under investigation, objectively and precisely. One important characteristic of scientific research is that data and method of analysis are quantitative. Thus, the scientific process of knowledge discovery in educational measurement is so reliant on the data and statistics.

Adding to the above point is a discussion by Magnusson (1966) on the two types of measurement. The first one being a physical measurement which is carried out in an objective manner using physical instruments that give fixed and precise scores in the form of centimetres, grams, time, etc. The second type of measurement is one that is concerned with psychological constructs. This measurement type is of major interest to many fields in education and social sciences. However, measurement of psychological constructs is problematic because these constructs such as attitude, intelligence, love, anxiety, happiness cannot be measured directly as it is the case with physical measurement. Magnusson (1966, pp.1) further notes that "in measuring such psychological constructs there is a need for objectivity, independence, neutrality or ability to think logically". Chadha (2009) argues that in the absence of a clearly defined instrument of measurement achievement of objectivity, independence or neutrality in measuring psychological variables is problematic. Hence, in measuring psychological attributes, measurement experts in psychological measurement field have developed a measurement scale based on the number system that is used to assign numbers to the quantities of the properties of objects following given rules whose extent of existence can later be tested empirically. For more reading on the scale of measurement see (Larry, 2013; Chadha, 2009; Murphy and Davidshofer, 2004).

Furthermore, the field of psychological measurement and assessment is interested in psychological constructs. Hence, in studying these psychological constructs a research design is needed to be able to ascertain the existence and measure important characteristics of construct, or variables. Educational psychologists are researchers themselves whose focus is on the application of psychology in educational settings through testing, measurement, and assessment as they attempt to solve educational problems (Reynolds and Livingston, 2011). Their involvement ranges from developing and analysing tests that are used in educational settings to educating teachers about how to develop better classroom assessments. Psychological assessment is important in every aspect of professional psychology. Hence, in developing and devising better education programs, measurement and evaluation experts adopt a certain paradigm as they engage in instrument development.

The above point relates to (Ergül, 2019, pp.4) who advanced that "paradigm can be considered as systems that meet the need to shape and make sense of reality". That is, a paradigm is responsible for directing people's actions. Kuhn (1996) notes that any scientific group cannot practise its trade without some set of received beliefs. Thus, we can say that various paradigms direct our actions. For example, adversarial paradigms guide the legal system, judicial paradigms, Olympic champions, religious paradigms, spiritual and spiritual experiences (Ergül, 2019). Hence, in terms of relationships to psychological assessment, it can be said that postpositivism paradigm guides the way of approaching, questioning and criticizing approaches and processes in psychological assessment.

Crocker and Algina (2006), give an important illustration relating the practice of psychological measurement in research. The two begin by illustrating that psychological attributes are hypothetical concepts that are products of the informed scientific imagination of a psychologist who attempts to develop theories for explaining human behaviour (Crocker and Algina, 2006). However, the existence of such constructs can never be confirmed. Therefore, the extent to which a psychological construct or attribute characterizes an individual can only be inferred from observations of his or her behaviour. Hence, these inferences are made following assumptions of a scientific research paradigm e.g., postpositivism paradigm concerned with making inferences.

To illustrate the point above lets we consider a researcher who aims to investigate the effects of computer 
integration in the junior secondary school curricula on students' performance. To investigate the effects of computer integration on student's performance, the researcher needs to formulate the problem, select a research design, engage in sampling, instrument development and carry out data analysis and interpretation e.g., inferential statistical analysis. To do all these, the researcher's choice of a methodology is influenced by a certain paradigm that guides everything from problem formulation to interpretation of the research results. Now the question is where the knowledge of measurement and assessment is applied in the scientific research process. To answer this question, we can say at the instrument development stage where the researcher can apply the knowledge of test theory to develop a test.

For instance, at the end of the year, the researcher can devise 50 items on general computer skills as applied in real life and administers them to all students. Items can be multiple-choice items scored with one point for each correct answer. The researcher can then compute a correlation between student grade point average scores and scores on the computer skills test. The researcher can then compute the mean number of items on the science test answered correctly for each group and compare these with a test of statistical significance. This illustration shows how psychological measurement tries to measure psychological constructs in solving educational problems. The psychological construct is based on theory, thus, engaging in psychological measurement is engaging in knowledge discovery aimed at improvement of programs or theory discovery (Crocker and Algina, 2006). Thus, the discovery of this knowledge follows research design, methods and procedures that are influenced by the postpositivists.

According to Murphy and Davidshofer (2004), statistical methods are used in the psychological assessment to describe scores. These methods are used to answer questions like how did people perform on the test? Did most people perform the same or were there large individual differences? The other part of research methods is inferential techniques that are used to make inferences about the meaning of test scores. It is clear here that the main research paradigm in psychological measurement is the postpositivist paradigm. This is because in psychological measurement the immediate goal of measurement is to assess quantitatively some attributes of participants taking the test items. To achieve this, psychological tests have set some rules or procedure for describing in quantitative or numeric terms participants behaviour in response to the test before drawing inferences (Murphy and Davidshofer, 2004). Hence, most research in the psychological assessment field takes the postpositivist approach. Gliner, Morgan and Leech mention that postpositivism assumes an objective reality that researchers should try to uncover as they engage in knowledge discovery (Gliner, Morgan, and Leech, 2017). The further point is by Christensen, Johnson, and Turner (2014) who grouped the sources of knowledge into three areas experiments, experts and reasoning. Mouly (1978) also categorised how the search for truth is achieved into three categories; experience, reasoning and research. However, Cohen, Manion, and Morrison (2007) argues that these are not independent of each other rather mutually exclusive, but complement and overlap each other. For instance, in searching for reality, researchers are heavily dependent on experience and authority but personal experience in a form of common-sense has limitations. Hence, the experience is quickly exposed when compared with the features of the scientific approach to research.

The point of interest here is rationalism a philosophical idea that reasoning is the primary source of knowledge. Cohen et al. (2007) divided reasoning into two, that is, inductive and deductive. The former involves moving from the specific to the general and builds a conclusion. The latter involves moving from the general to the specific and conclude if a valid form of argument is used and its premises are true (Christensen et al., 2014). Thus, rationalism is of key importance in psychological assessment where researchers mainly start with a hypothesis based on theory, collect data to be used to test the hypothesis and decides to accept or reject the hypothesis based on the data. In concluding the three noted that the pure positivist approach is deductive, within the approach we find experimental and non-experimental designs, quantitative data and statistical methods (Christensen et al., 2014).

Crocker and Algina (2006), whenever quantitative values are assigned to the behavioural sample collected by using a test, measurement of the psychological attribute is said to have occurred. Put simply, a measurement has taken place when the educator writes the number of behavioural acts on the checklist that a child displayed during a five-minute observation period, or when the computer instructor counts the number of items a student answered correctly on computer test skills and records the total score. Therefore, from measurements of such observable behaviour, measurement and assessment experts can draw inferences about the amount of the theoretical construct that characterizes an individual.

This section ends with the point that to determine the extent, dimension or magnitude of something, or to establish the attribute of something with precision, researchers so often resort to measurement. This helps them to gather quantitative data about objects, phenomena, systems or psychological attributes. Hence, this quantitative data which is gathered using measurement rules and procedures are more precise and easier to work with than non-quantitative data, which is generally vague and quite misleading. Therefore, specialists in measurement and evaluation fields, by using measurement with the help of mathematical models and statistics can differentiate psychological attributes, and predicate or explain relationship amongst them with a greater 
degree of refinement and exactness. Thus, measurement is an essential element of scientific investigation and knowledge discovery.

\section{Suggestions for Discussing Quantitative Versus Qualitative Research}

Today the quantitative versus qualitative debate has continued as though one or the other should eventually win. However, in approaching this discussion it is convenient to start discussing them at paradigm level before anything else. Scholars like Gliner and Morgan (2000) categorized them as dichotomy on three levels with the first one being the philosophical or paradigm differences in the approach to research (positivists versus constructivists). Thus, in this paper, it was considered prudent to introduce readers to paradigms in scientific research before talking about the main topic of the paper. Further, discussing paradigms was imperative because much of the questions that are asked today in the scientific research community on paradigms, methodology, approach and design have their roots in scientific research paradigms. This is so because scientific research paradigms are inseparable with the research methodology, approach and design. That is, for one to plan and conduct his or her research, read and critique the research of others, and join in the philosophical, theoretical, and methodological debates in the research community, he or she needs to have an understanding of the prevailing paradigms, with their underlying philosophical assumptions.

Thus, at this point, readers should be able to understand the importance of scientific research paradigms in discussing qualitative versus quantitative dichotomies in research. Four major paradigms influencing researchers and evaluators have been briefly described in this paper as follows: Postpositivism emphasizes objectivity, experimentation, and generalizability. Constructivism emphasizes constructed realities, interaction with participants, and rich description. Advocacy or transformative paradigm focus on issues of social justice, human rights, and cultural complexity. Pragmatic researchers match the research questions with the choice of research methods, as indicated by each specific study's demands. When one critically follows these paradigms three methodological issues come out: qualitative, quantitative and mixed methods. Hence, at the paradigm level, the discussion on the qualitative versus quantitative research is between the postpositivists and constructivists researchers. The discussion here is centred on the methodological issues. The postpositivists follow the quantitative methodology. This is the methodology of interest especially among researchers in psychological measurement and assessment. On the other hand, constructivists use primarily a qualitative methodology.

The two methodologies cannot be combined without considering the underlying assumptions of the paradigm underpinning them. However, based on the assumptions of pragmaticism and transformative paradigms the two methodologies complement each other. This is where mixed-method comes in. Pragmatist researchers in their methodology match methods to specific questions and purposes of research. Thus, using mixed methods researcher work back and forth between various approaches and methods. The point here is that the researcher is interested in both quantitative and qualitative information to maximize the validity of the study. Arguably, the researcher works on the continuum of quantitative and qualitative information, that is, the moment a researcher seeks for more objective data quantitative methods are used. Conversely, qualitative methods are used whenever a researcher wants more subjective information reflective of individuals own interpretation. Hence, the paper has discussed quantitative versus qualitative research as being on a continuum.

\section{Acknowledgement}

The authors wish to express gratitude to the Department of Measurement and Evaluation in Education for the opportunity to learn with the incredibly knowledgeable and caring professors at Mersin University. Their support and contributions are much appreciated.

\section{Financial support and sponsorship}

Nil.

\section{Conflicts of interest}

There are no conflicts of interest.

\section{References}

Biggerstaff, D. (2012), “Qualitative Research Methods in Psychology”, Psychology in Selected Papers, 6(23).

Blumer, H. (1980), "Mead and Blumer: The Convergent Methodological Perspectives of Social Behaviourism and Symbolic Interactionism", American Sociological Review, 45(3): 409

Bother, W. (2011), "An Introduction to Research", Resources for Nursing Research, 18-28.

Burrell, G., \& Morgan, G. (1979), "Sociological Paradigms and Organizational Analysis”, UK: Gower

Chadha, N. K. (2009), "Applied Psychometry", London: SAGE Publications.

Cherryholmes, C. H. (1992), "Notes on Pragmatism and Scientific Realism”, Educational Researcher, Volume $21(6)$, p $13-17$ 
Christensen, L.B., Johnson, R.B., \& Turner, L.A. (2015), “Research Methods, Design and Analysis”, Edinburg: Pearson Education Limited

Clegg, J.W. \& Slife, B.D. (2009), “The Handbook of Social Research Ethics”, New York: SAGE

Cohen, L., Manion, L., \& Morrison, K. (2007), "Research Methods in Education”, New York: Routledge

Creswell, J. W. (2013), "Qualitative, Quantitative, and Mixed Methods Approaches”, London: SAGE

Creswell, J. W. (2014), "The Selection of a Research Approach", Research Design: Qualitative, Quantitative and Mixed-Methods Approaches, 3-23.

Crocker, L. \& Algina, J. (2008), "Introduction to Classical and Modern Test Theory", USA: Cengage Learning

Crotty, M. (1998), "The foundations of social research: Meaning and perspective in the research process", Thousand Oaks, CA: Sage

Ergül, D. (2019), "Ölçme Ve Değerlendirme Anabilim Dali Notlarim: Bilimsel Araştirma Paradigmalari”, Ankara: Ankara Üniversitesi

Fay, B. (1987), "Critical Social Science: Liberation and its Limits", Cornell: Cornell University Press

Firstone, W.A. (1987), "Meaning in Method: The Rhetoric of Quantitative and Qualitative Research", Educational Researcher, 16(7), 16-21

Foucault, M. (1980), "Power/Knowledge", Sussex: Harvester Press

Freire, P. (1974), "Freire Education for Critical Consciousness", London: Continuum.

Gliner, A. J., Morgan, A. G., \& Leech, L. N. (2017), "Research Methods in Applied Settings: An Integrated Approach to Design and Analysis (3rd Ed.)", New York: Routledge.

Gliner, J.A., \& Morgan, G.A. (2000), "Research Methods in Applied Settings: An Integrated Approach to Design and Analysis", London: Lawrence Erlbaum Associates, Publishers

Gray, P. S., Williamson, J. B., Karp, D. A., \& Dalphin, J. R. (2007), "The Research Imagination: An Introduction to Qualitative and Quantitative Methods", Cambridge: Cambridge University Press

Gray, S. P., Williamson, B. J., Karp, A. D., \& Dalphin, R. J. (2007), "The Research Imagination. An Introduction to Qualitative and Quantitative Methods", New York: Cambridge University press

Guba, E. G., \& Lincoln, Y. S. (1989), "Fourth generation evaluation”, Newbury Park, CA: Sage.

Guba, E. G., \& Lincoln, Y. S. (2005), Paradigmatic controversies, contradictions, and emerging confluences. In N. K. Denzin and Y. S. Lincoln. The Sage handbook of qualitative research (3rd ed.). Thousand Oaks, CA: Sage

Heron, J., \& Reason, P. (1997), “A participatory inquiry paradigm”, Qualitative Inquiry, 3, 274-294

Hoy, W. \& Adams, C. (2015), "Quantitative research in education”, London, United Kingdom: Sage

Kane, M. T. (2013), "Validation as a Pragmatic, Scientific Activity", Journal of Educational Measurement, $50(1), 115-122$

Kemmis, S., \& Wilkinson, M. (1998), "Participatory action research and the study of practice", In B. Atweh, S. Kemmis, and P. Weeks (Eds.). Action research in practice: Partnerships for social justice in education. New York: Routledge

Kothari, C. R. (2004), "Research Methodology: Methods and techniques (2nd ed.)", New Age International.

Kress, T.M \& Lake, R. (Eds.). (2013), "We Saved the Best for You. Letters of Hope, Imagination and Wisdom for 21st Century Educators", Rotterdam: Sense Publishers

Kuhn, T. S. (1996), "The Structure of Scientific Revolutions (3rd Ed.)”, Chicago: The University of Chicago Press

Ladson-Billings, G. (2000), "Racialized Discourses and Ethnic Epistemologies", Handbook of qualitative research 2, 257-277

Ladson-Billings, G., \& Donnor, J. (2005), “The Moral Activist Role of Critical Race Theory Scholarship”, In N. K. Denzin \& Y. S. Lincoln (Eds.), The Sage handbook of qualitative research (pp. 279-301). Thousand Oaks, CA: Sage Publications

Lake, R., \& Kress, T. (Eds.). (2013), "Paulo Freire's Intellectual Roots: Toward Historicity in Praxis”, London: Bloomsbury Academic

Lake, R., \& Kress, T. (Eds.). (2013), “Paulo Freire’s Intellectual Roots: Toward Historicity in Praxis”, London: Bloomsbury Academic

Larry, R. P. (2013). Psychometric Methods: Theory into Practice. New York: The Guilford Press

Lather, P. (1992), "Critical Frames in Educational Research: Feminist and Post-structural Perspectives", Theory into Practice XXXI, 2

Lather, P. (1995), "The validity of angels: Interpretive and textual strategies in researching the lives of women with HIV/AIDS", Qualitative Inquiry, 1(1), 41-68.

Lichtman, M. (2006), "Qualitative Research in Education: A User's Guide”, London: SAGE

Magnusson, D. (1966), "Test Theory”, Massachusetts: Addison-Wesley Publishing

Masterman, M. (1970), “The Nature of a Paradigm”, Cambridge: Cambridge Language Research Unit

Morgan, D. L. (2007), "Paradigms Lost and Pragmatism Regained: Methodological Implications of Combining 
Qualitative and Quantitative Methods", Journal of mixed methods research 1(1), 48-76

Mumba, B., \& Alıc1, D. (2019), “Understanding Quantitative versus Qualitative Dichotomies”, Social Sciences Educational Journal, 2(7).

Murphy, G. J. (1990), “The science of educational research”, New York: Litton Educational.

Murphy, R. K., and Davidshofer, O. C. (2004), "Psychological Testing- Principles and Applications (6th Ed.)", New Jersey: Pearson Education.

Newman, C., and Benz, C. (1998), "Qualitative-Quantitative Research Methodology: Exploring the Interactive Continuum", Carbondale and Edwardsvillie: Southern Illinois University Press

Orman, T. (2016), "Paradigm as a Central Concept in Thomas Kuhn's Thought", Paediatric Emergency Care, $6(10)$

Patton, M. Q. (2002), “Qualitative Research and Evaluation Methods”, Thousand Oaks, CA: Sage Publications

Phillips, D. C., \& Burbules, N. C. (2000), "Postpositivism and educational research", Lanham, MD: Rowman \& Littlefield.

Reynolds, C.R, \& Livingston, R.B. (2014), "Mastering Modern Psychological Testing: Theory and Methods", Edinburgh Gate: Pearson Education Limited

Rossman, G.B., \& Wilson, B.C. (1985), "Number and Words: Combing Qualitative and Quantitative Method in a Single Large-Scale Evaluation Study", Evaluation Review, 9(5), 627-643

Schwandt, T. A. (2000), "Three Epistemological Stances for Qualitative Inquiry", In N.K. Denzin and Y.S. Lincoln (Eds.). Handbook of Qualitative Research (2nd ed). Thousand Oaks CA: SAGE

Singh, Y.K. (2006), "Fundamental of Research Methodology and Statistics", New Delhi: New Age International Limited Publishers

Smith, G. P. (1992), "An Introduction to the Philosophy of Science: Theory and Reality", Chicago: The University of Chicago Press

Smith, R.P. (1981), "Naturalistic Research", Social Research, 48(4):766-785

St. Pierre, E. A. (2000), "The Call for Intelligibility in Postmodern Educational Research", Educational Researcher, 29(5), 25-28.

Tashakkori, A., \& Teddlie, C. (Eds.). (2003), "Handbook of Mixed Method Research in the Social and Behavioral Sciences", Thousand Oaks CA: SAGE 